DOI: 10.1515/amm-2016-0067

W. GĄSIOR*\#, J. PSTRUŚ*, Z. MOSER**

\title{
INFLUENCE OF ZINC ON THE SURFACE TENSION, DENSITY AND MOLAR VOLUME OF (Ag-Sn) EUT +Zn LIQUID ALLOYS
}

\begin{abstract}
The dilatometric and maximum bubble pressure methods were applied for the measurements of the density and surface tension of liquid $(\mathrm{Ag}-\mathrm{Sn})_{\text {eut }}+\mathrm{Zn}$ lead-free solders. The experiments were carried out in the temperature range from 515 to 1223 $\mathrm{K}$ for the alloys of the zinc concentration equaling $0.01,0.02,0.04,0.05,0.1$ and 0.2 of the mole fraction. It was found that the temperature dependence of both the density and the surface tension could be thought as linear, so they were interpreted by straight line equations. The experimental data of the molar volume of the investigated alloys were described by the polynomial dependent on the composition and temperature.

Calculations of the surface tension by Butler's equation were conducted and confronted with the experimental data. Some significant deviations between the experimental and the calculated surface tension were observed. They reached almost $40 \mathrm{mNm}^{-1}$. The observed changes of the density and surface tension caused by the zinc addition to the Ag-Sn eutectic were discussed with the consideration of the thermodynamic properties and the influence of a small quantity of impurities in a protective gas atmosphere.
\end{abstract}

\section{Introduction}

The measurements of the physicochemical properties, such as the surface tension, density and viscosity, of the low-temperature lead-free solders have been carried out at the Institute of Metallurgy and Materials Science for more than 20 years. They have been the result of the decision of the European Union and other countries in the world to eliminate a number of substances harmful to the health and the environment, including certain metals, such as lead. These studies have led to the development of new lead-free solders for electronics and electrical engineering. Initially, the research for the physical properties was focused on binary systems ( $\mathrm{Pb}-\mathrm{Sn}[1,2]$ and Ag-Sn [3]), and then, it was expanded to multicomponent systems on the base of the AgSn eutectic, including also wettability and microstructural studies $[4,5]$. The studies were also carried out in the frames of the programs COST 531 (low-temperature solders) [6, 7] and COST MP 0602 (high temperature solders) [8], as well as projects financed by the Polish Government and in the cooperation with Tohoku University and industrial Institutes [9].

The determination of the physicochemical properties was conducted at our Institute by the maximum bubble pressure method for the surface tension, the dilatomeric method for the density and the capillary flow method for the dynamic viscosity. The series of studies concerned the impact of different metals (modifiers) on the properties of the Ag-Sn eutectic, including the $(\mathrm{Ag}-\mathrm{Sn})_{\text {eut }}+\mathrm{Zn}$ alloys.

There is a very limited number of articles on the experimental studies of the thermodynamic properties of the tin-silver-zinc system, and as regards the physicochemical properties which will be presented in this work, we have not found even one work, except the one on the theoretical data for the surface tension and viscosity obtained by [10] at $900 \mathrm{~K}$ with the use of models selected from the literature.

Because of the total lack of experimental results of the density and surface tension, experimental investigations were proposed and conducted by the authors, and the results are presented in this article together with the modeled data of the surface tension and surface composition in the monoatomic surface layer, calculated by models based on the thermodynamic properties of the Ag-Sn-Zn liquid solutions given in paper [11] and the physical properties of metals which form alloys.

\section{2. Experimental methods and modelling}

\subsection{Preparation of alloys}

The $(\mathrm{Ag}-\mathrm{Sn})_{\text {eut }}+\mathrm{Zn}$ alloys were prepared in a graphite crucible by way of melting a suitable amount of silver $(99.995 \%)$, tin $(99.999 \%)$ and zinc $(99,99 \%)$ directly before the experiments. The preparation was conducted in a glovebox with the protective atmosphere of high-purity argon, which continuously circulated in the purification system (molecular sieve, catalytic copper and Ti). The concentration of oxygen and water vapour in the protective atmosphere of the glovebox was much below $1 \mathrm{pp}$. The nitrogen was not monitored, but it was absorbed by the Ti-sponge at an elevated temperature. The protective atmosphere of a high purity gas mixture of Ar

\footnotetext{
* ALEKSANDER KRUPKOWSKI INSTITUTE OF METALLURGY AND MATERIALS SCIENCE, POLISH ACADEMY OF SCIENCES, 25 REYMONTA STR., 30-059 KRAKÓW, POLAND ** IN MEMORY

\# Corresponding author: w.gasior@imim.pl
} 
+10 vol. $\% \mathrm{H}_{2}$ was used during the measurements of both the surface tension and the density.

\subsection{Surface tension measurement}

The surface tension measurements of the $(\mathrm{Ag}-\mathrm{Sn})_{\mathrm{eut}}+\mathrm{Zn}$ liquid alloys were performed by the maximum bubble pressure method, and the surface tension in the first approximation was calculated based on the known capillarity equation:

$$
\sigma=\frac{1}{2} \mathrm{r} \Delta \mathrm{p} \quad[\mathrm{N} / \mathrm{m}]
$$

describing the relation between the surface tension $\sigma$, the radius of the capillary $r$ and the pressure $\Delta p$ necessary to form and to detach the gas bubble from the end of the capillary. The $\Delta \mathrm{p}$ is, in fact, the pressure difference between the gas pressure and the hydrostatic pressure of the liquid alloy, and it is given by the following equation:

$$
\Delta \mathrm{p}=\mathrm{p}_{\mathrm{g}}-\mathrm{p}_{\mathrm{h}} \quad\left[\mathrm{N} / \mathrm{m}^{2}\right]
$$

$$
\mathrm{p}_{\mathrm{h}}=\rho g \mathrm{~h}_{\mathrm{d}} \quad\left[\mathrm{N} / \mathrm{m}^{2}\right]
$$

In Eqs. 3 and 4, $p_{g}$ is the gas pressure, $p_{\mathrm{h}}$ is the hydrostatic pressure of the alloy, $g$ is the acceleration of gravity, $\rho$ is the density of the investigated liquid alloy and $h_{d}$ is the immersion depth of the capillary.

Because the surface tension calculated from Eq. 2 is only an approximate value, the exact value of surface tension was calculated with the use of the method proposed by Sugden [12]. The experimental apparatus was described and schematically shown in our previous paper [13].

\subsection{Density measurements}

The density study of the silver-tin-zinc liquid alloys was performed by the dilatometric method [13] based on the measurements of the height of the liquid alloy in the crucible at constant temperatures. The determination of the density was conducted with the use of the mentioned below relation:

$$
\rho=\frac{4 \mathrm{~m}}{\pi \mathrm{d}^{2} \mathrm{~h}} \quad\left[\mathrm{~kg} / \mathrm{m}^{3}\right]
$$

where: $r$ is the density, $m$ is the mass of the metal or alloy, $d$ is the crucible diameter and $\mathrm{h}$ is the height of the metal or alloy in the crucible.

Both in case of the surface tension and the density studies, corrections of the thermal expansion of the crucible and the capillary were performed.

\subsection{Surface tension modelling}

It was already mentioned that there is a possibility to predict the surface tension of alloys using the method proposed by Butler [14]. The equation describing the composition and temperature dependence of the surface tension for the liquid $\mathrm{Ag}-\mathrm{Sn}-\mathrm{Zn}$ alloys takes the following form:

$$
\begin{aligned}
& \sigma=\sigma_{\mathrm{Ag}}+\frac{\mathrm{RT}}{\mathrm{A}_{\mathrm{Ag}}} \ln \frac{\mathrm{X}_{\mathrm{Ag}}^{\mathrm{S}}}{\mathrm{X}_{\mathrm{Ag}}^{\mathrm{B}}}+\frac{1}{\mathrm{~A}_{\mathrm{Ag}}}\left[\mathrm{G}_{\mathrm{Ag}}^{\mathrm{ES}}\left(\mathrm{T}, \mathrm{X}_{\mathrm{Ag}}^{\mathrm{S}}, \mathrm{X}_{\mathrm{Sn}}^{\mathrm{S}}, \mathrm{X}_{\mathrm{Zn}}^{\mathrm{S}}\right)-\mathrm{G}_{\mathrm{Ag}}^{\mathrm{E}, \mathrm{B}}\left(\mathrm{T}, \mathrm{X}_{\mathrm{Ag}}^{\mathrm{B}}, \mathrm{X}_{\mathrm{Sn}}^{\mathrm{B}}, \mathrm{X}_{\mathrm{Zn}}^{\mathrm{B}}\right)\right] \\
& =\sigma_{\mathrm{Sn}}+\frac{\mathrm{RT}}{\mathrm{A}_{\mathrm{Bi}}} \ln \frac{X_{\mathrm{Sn}}^{\mathrm{S}}}{\mathrm{X}_{\mathrm{Sn}}^{\mathrm{B}}}+\frac{1}{\mathrm{~A}_{\mathrm{Sn}}}\left[\mathrm{G}_{\mathrm{Sn}}^{\mathrm{E}, \mathrm{S}}\left(\mathrm{T}, \mathrm{X}_{\mathrm{Ag}}^{\mathrm{S}}, \mathrm{X}_{\mathrm{Sn}}^{\mathrm{S}}, \mathrm{X}_{\mathrm{Zn}}^{\mathrm{S}}\right)-\mathrm{G}_{\mathrm{Sn}}^{\mathrm{E}, \mathrm{B}}\left(T, X_{\mathrm{Ag}}^{\mathrm{B}}, \mathrm{X}_{\mathrm{Sn}}^{\mathrm{B}}, \mathrm{X}_{\mathrm{Zn}}^{\mathrm{B}}\right)\right] \\
& =\sigma_{\mathrm{Zn}}+\frac{\mathrm{RT}}{\mathrm{A}_{\mathrm{Zn}}} \ln \frac{X_{\mathrm{Zn}}^{\mathrm{S}}}{\mathrm{X}_{\mathrm{Zn}}^{\mathrm{B}}}+\frac{1}{\mathrm{~A}_{\mathrm{Zn}}}\left[\mathrm{G}_{\mathrm{Zn}}^{\mathrm{ES}}\left(T, X_{\mathrm{Ag}}^{\mathrm{S}}, \mathrm{X}_{\mathrm{Sn}}^{\mathrm{S}}, \mathrm{X}_{\mathrm{Zn}}^{\mathrm{S}}\right)-\mathrm{G}_{\mathrm{Zn}}^{\mathrm{E}, \mathrm{B}}\left(\mathrm{T}, \mathrm{X}_{\mathrm{Ag}}^{\mathrm{B}}, \mathrm{X}_{\mathrm{Sn}}^{\mathrm{B}}, \mathrm{X}_{\mathrm{Zn}}^{\mathrm{B}}\right)\right]
\end{aligned}
$$

This equation relates the surface tension of the given solution to the property of the pure metal, as well as to the surface area of the metallic monolayer and the thermodynamic activity of the components in the surface and the bulk phases.

In Eq. 5, $\mathrm{R}$ is the gas constant, $\mathrm{T}$ is the temperature, $\sigma_{\mathrm{i}}$ is the surface tension, $A_{\mathrm{i}}$ is the molar surface area in the monolayer and $X_{i}^{B}$ and $X_{i}^{S}$ is the mole fraction of metal i ( $\mathrm{i}=$ $\mathrm{Ag}, \mathrm{Sn}, \mathrm{Zn})$ in the surface and the bulk phase, respectively $\left(X_{A g}^{B(S)}+X_{S n}^{B(S)}+X_{Z n}^{B(S)}=1\right)$. The molar surface area $\mathrm{A}_{\mathrm{i}}$ is calculated by way of applying the equation:

$$
\mathrm{A}_{\mathrm{i}}=\mathrm{LN}^{1 / 3} \mathrm{~V}_{\mathrm{i}}^{2 / 3}
$$

In Eq.6, $\mathrm{N}$ is Avogadro's number, and $\mathrm{V}_{\mathrm{i}}$ is the molar volume of pure liquid metal i, L is usually set to be 1.091 for liquid metals assuming close packed structures proposed by HoarMelford [15], $\mathrm{G}^{\mathrm{E}, \mathrm{S}}$ and $\mathrm{G}^{\mathrm{E}, \mathrm{B}}$ are the partial excess Gibbs energies of component $i$ in the surface and the bulk phase. The excess Gibbs energies are functions of $\mathrm{T}$ and the mole fraction of components $\mathrm{i}(\mathrm{Xi})$ and finally, the relationship between the excess Gibbs energy of component $i$ in the bulk and in the surface phase is assumed to be as follows:

$$
G_{i}^{E, S}\left(T, X_{A g}^{S}, X_{S n}^{S}, X_{Z n}^{S}\right)=\beta G_{i}^{E, B}\left(T, X_{A g}^{S}, X_{S n}^{S}, X_{Z n}^{S}\right)
$$

$\beta$ is the parameter corresponding to the ratio of the coordination number $\mathrm{Z}$ in the surface phase to that in the bulk phase $Z^{\mathrm{S}} / \mathrm{Z}^{\mathrm{B}}$. After Tanaka et al. [16], it is assumed to be equal to 0.83 for liquid metals.

In earlier publications, [17-21], a qualitative agreement was observed between the experimental and the calculated surface tensions from Butler's model; however, the calculations have shown the increase of the surface tension vs. temperature (the positive temperature coefficient), the reasonable differences between the experimental and modelled data and also the curvilinear dependence of the surface tension vs. temperature (sometimes with the maximum) while from the experiment the straight line dependence vs. T with the negative value of temperature coefficient was observed. This was the main reason of the discussion of that problem conducted in [22] and [23].

The analysis of the influence of $\beta$ and the monoatomic surface layer area $A_{i}$ on the surface tension calculated (Eqs 5-7) for some binary alloys $[22,23]$ has shown that the dominant parameter which influences the calculated surface tension is the monoatomic surface layer area $\mathrm{A}_{\mathrm{i}}$. With the assumption that the temperature dependence of the surface tension of alloys should be (almost) linear, as it was observed from the 
experiments, new equations for the determination of $A_{i}$ and $\beta$ were proposed. It was also shown $[20,22]$ that the excess Gibbs free energy calculated from the surface tension measurements was comparable with that determined from the other methods used especially for the measurement of the mentioned above thermodynamic property. In the work on the modelling of the surface tension and the excess free energy for the Fe-Ni and Fe-Co binary liquid alloys [24], it was shown that the surface tension and excess free Gibbs energy calculated with the use of relations (5-7) showed a much worse correlation with the experimental data in comparison to that obtained with the use of the relations for $A_{i}$ and $\beta$ proposed in the work [22, 23], which are given by the relations below:

$$
A=1.091 \sum_{\mathrm{i}=1}^{\mathrm{n}} \mathrm{k}_{\mathrm{r}(\mathrm{i})}^{2} \mathrm{X}_{\mathrm{S}(\mathrm{i})}\left[\sum_{\mathrm{i}=1}^{\mathrm{n}} \mathrm{V}_{\mathrm{i}} \mathrm{X}_{\mathrm{S}(\mathrm{i})}\right]^{2 / 3} \mathrm{~N}^{1 / 3}
$$

or for the linear changes of the monoatomic molar surface area

$$
\begin{gathered}
A=1.091 \mathrm{~N}^{1 / 3} \sum_{\mathrm{i}=1}^{\mathrm{n}} \mathrm{k}_{\mathrm{r}(\mathrm{i})}^{2} V_{i}^{2 / 3} \mathrm{X}_{\mathrm{S}(\mathrm{i})} \\
\mathrm{A}_{\mathrm{i}} \sigma_{\mathrm{i}}=\left(1-\beta_{\mathrm{i}}\right)\left(\mathrm{G}_{\mathrm{g}}^{\mathrm{o}}-\mathrm{G}_{\mathrm{c}}^{\mathrm{o}}\right) \\
\mathrm{G}_{\mathrm{S}}^{\mathrm{ex}}=\left[\sum_{\mathrm{i}=1}^{\mathrm{n}} \beta_{\mathrm{i}} \mathrm{X}_{\mathrm{S}(i)}\right]\left[\mathrm{G}_{\mathrm{B}}^{\mathrm{ex}}\left(\mathrm{X}_{\mathrm{S}(1)} \ldots . X_{S(i-1)}\right)\right]
\end{gathered}
$$

Where: $\beta$ is the coefficient characterizing the difference between the coordination number of atoms in the bulk and in the surface phase, $\mathrm{A}$ is the molar monoatomic surface area, $\mathrm{kr}_{(\mathrm{i})}$ is the correction parameter (calculations of $\mathrm{k}_{\mathrm{r}}$ are given in [20]), $\mathrm{V}_{\mathrm{i}}, \mathrm{S}_{\mathrm{i}}, \mathrm{A}_{\mathrm{i}}$ and $\sigma_{\mathrm{i}}$ are the molar volume, the molar surface areas, the surface layer area and the surface tension of metal $i$, respectively, $G_{g}^{o}-G_{c}^{o}$ is the transformation standard free energy change of 1 mole of metal atoms (i) into its monoatomic gas at its melting temperature (Tanaka et al. [16] used the heat of vaporization in the $\beta$ calculation (Eq. 9)).

Parameters $\beta$ and $\mathrm{k}_{\mathrm{r}}$ were determined according to the procedure presented in works [22] and [23], and for Ag, Sn and $\mathrm{Zn}$, the temperature dependences are given in Table 1 .
TABLE 1

Temperature dependences of $\mathrm{k}_{\mathrm{r}}$ and $\beta$ parameters from Eqs 6, 8-11 for $\mathrm{Ag}$, Sn and $\mathrm{Zn}$.

\begin{tabular}{|c|c|}
\hline \hline $\mathrm{kr}$ & $\beta$ \\
\hline $\mathrm{k}_{\mathrm{r}(\mathrm{Ag})}=0.8789-0.0001477 \mathrm{~T}$ & $\beta_{\mathrm{Ag}}=0.8125+0.0001186 \mathrm{~T}$ \\
$\mathrm{k}_{\mathrm{r}(\mathrm{Sn})}=1.0154-0.0001453 \mathrm{~T}$ & $\beta_{\mathrm{Sn}}=0.5328+0.0002514 \mathrm{~T}$ \\
$\mathrm{k}_{\mathrm{r}(\mathrm{Zn})}=0.4110-0.0000574 \mathrm{~T}$ & $\beta_{\mathrm{Zn}}=0.2687+0.0009751 \mathrm{~T}$ \\
\hline
\end{tabular}

\section{Results and discussion}

The experimental results of the density (Fig. 1), similarly to those of many metallic systems, characterize in a linear change with temperature (Fig. 1), so they were elaborated by straight line equations applying the least square method. The equations are presented in Table 2 together with the errors calculated for the equation parameters (A, B) and for the surface tension at 923 $\mathrm{K}$, according to the procedure given in the references [26].

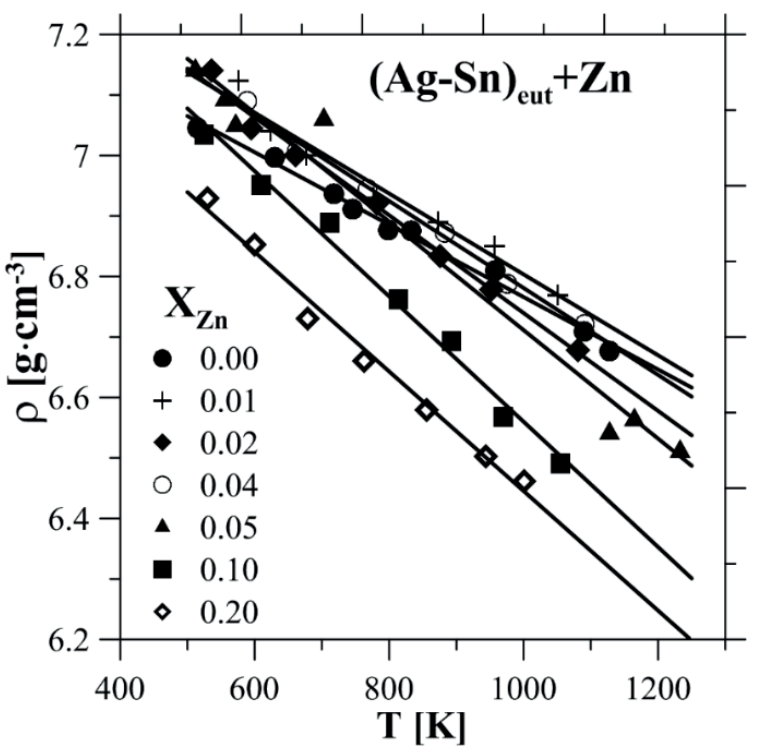

Fig. 1. Temperature dependences of density for the $(\mathrm{Ag}-\mathrm{Sn})_{\text {eut }}+\mathrm{Zn}$ liquid alloys. Symbols show the experimental data from these studies and the lines represent the values calculated by equations in Table 1 .

TABLE 2 Temperature dependences of density for $(\mathrm{Ag}-\mathrm{Sn})_{\text {eut }}+\mathrm{Zn}$ liquid alloys with errors calculated for $\mathrm{A}$ and $\mathrm{B}$ equation parameters and density error calculated at $923 \mathrm{~K}$

\begin{tabular}{|c|c|c|c|c|}
\hline \hline $\mathbf{X}_{\mathbf{Z n}}$ & $\begin{array}{c}\boldsymbol{\rho}=\mathbf{A}+\mathbf{B} \cdot \mathbf{T} \\
\mathrm{g} \cdot \mathrm{cm}^{-3}\end{array}$ & $\begin{array}{c}\boldsymbol{\rho} \text { 923K } \\
\mathrm{g} \cdot \mathrm{cm}^{-3}\end{array}$ & $\begin{array}{c}\operatorname{Err}(\mathbf{A}) \\
\mathrm{g} \cdot \mathrm{cm}^{-3}\end{array}$ & $\begin{array}{c}\operatorname{Err}(\mathbf{B}) \\
\mathrm{g} \cdot \mathrm{cm}^{-3} \cdot \mathrm{K}^{-1}\end{array}$ \\
\hline $0.0000^{*}$ & $7.3645-0.000599 \cdot \mathrm{T}$ & $6.812 \pm 0.028$ & \pm 0.040 & \pm 0.000047 \\
\hline 0.0100 & $7.4718-0.000668 \cdot \mathrm{T}$ & $6.855 \pm 0.058$ & \pm 0.104 & \pm 0.000129 \\
\hline 0.0200 & $7.5480-0.000809 \cdot \mathrm{T}$ & $6.802 \pm 0.040$ & \pm 0.064 & \pm 0.000080 \\
\hline 0.0400 & $7.4996-0.000719 \cdot \mathrm{T}$ & $6.836 \pm 0.032$ & \pm 0.061 & \pm 0.000072 \\
\hline 0.0500 & $7.6082-0.000897 \cdot \mathrm{T}$ & $6.780 \pm 0.109$ & \pm 0.122 & \pm 0.000136 \\
\hline 0.1000 & $7.5955-0.001036 \cdot \mathrm{T}$ & $6.640 \pm 0.057$ & \pm 0.095 & \pm 0.000136 \\
\hline 0.2000 & $7.4335-0.000988 \cdot \mathrm{T}$ & $6.521 \pm 0.053$ & \pm 0.091 & \pm 0.000116 \\
\hline
\end{tabular}


Next, the molar volumes of the investigated alloys were calculated at four temperatures $(523 \mathrm{~K}, 723 \mathrm{~K}, 923 \mathrm{~K}, 1123$ $\mathrm{K})$ with the application of the density equations in Table 2, and their values were described by the parabolic equation dependent on the zinc mole fraction and temperature:

$$
\begin{aligned}
V_{m}=(15.9841+ & 0.0015 \mathrm{~T})+(-20.1181+0.015572 \mathrm{~T}) X_{Z n} \\
& +(58.6011-0.0543 \mathrm{~T}) X_{Z n}^{2}
\end{aligned}
$$

The molar volumes calculated with the application of Eq. 12 for the four temperatures are presented in Fig. 2 on the background of the experimental data (Table 2).

As one can notice from Fig. 2, the $\mathrm{Zn}$ addition to the AgSn eutectic causes, at $523 \mathrm{~K}$ and $723 \mathrm{~K}$, a slight lowering, and at $1123 \mathrm{~K}$, a slight increase of the molar volume in comparison to the linear one between the Ag-Sn eutectic and zinc. In the case of density isotherms (Fig.3) at the lowest temperature $(523 \mathrm{~K})$ and for low $\mathrm{Zn}$ concentrations, a growth of density of the Ag-Sn-Zn alloys is observed. This tendency steadily decreases with the increase of temperature. The increase of the density is the effect of the decrease of the molar volume. For comparison's sake, Fig. 3, shows also the values measured by Pstruś [27] and the linear changes of density in the $\mathrm{Sn}-\mathrm{Zn}$ system (thin line). The density of the $\mathrm{Sn}-\mathrm{Zn}$ alloys presented in our earlier work [28] was almost like the one of the ideal alloy (almost the same as the thin line shows).

One can try to explain this increase of density of the liquid $(\mathrm{Ag}-\mathrm{Sn})_{\text {eut }}+\mathrm{Zn}$ alloys with the increase of the zinc concentration based on the thermodynamic properties of binary systems and by the intuitive hypothesis that the systems with negative deviations from the ideal ones should be of a higher density (lower molar volume) than those of positive deviations and that of the ideal one. Such behavior was observed, for example, in solid Al-Li, Li-Mg and Al-Li-Mg alloys [29, 30, $31]$ and $\mathrm{Li}-\mathrm{Mg}$ or $\mathrm{Li}-\mathrm{Pb}[32,33]$ or in the case of many other binary liquid alloys with alkaline metals [34] which possess negative deviations from the ideal solutions, as well as in the case of the $\mathrm{Pb}-\mathrm{Sn}$ system [1] with positive deviations.

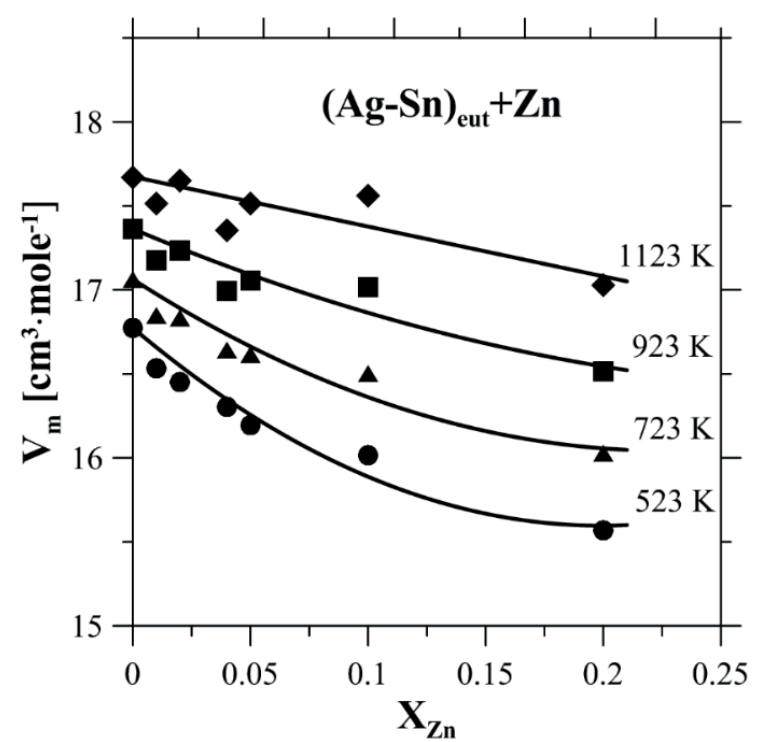

Fig. 2. Molar volume isotherm of the $(\mathrm{Ag}-\mathrm{Sn})_{\text {eut }}+\mathrm{Zn}$ liquid alloys. Symbols show the experimental data and the lines represent the data calculated by Eq. 12 .

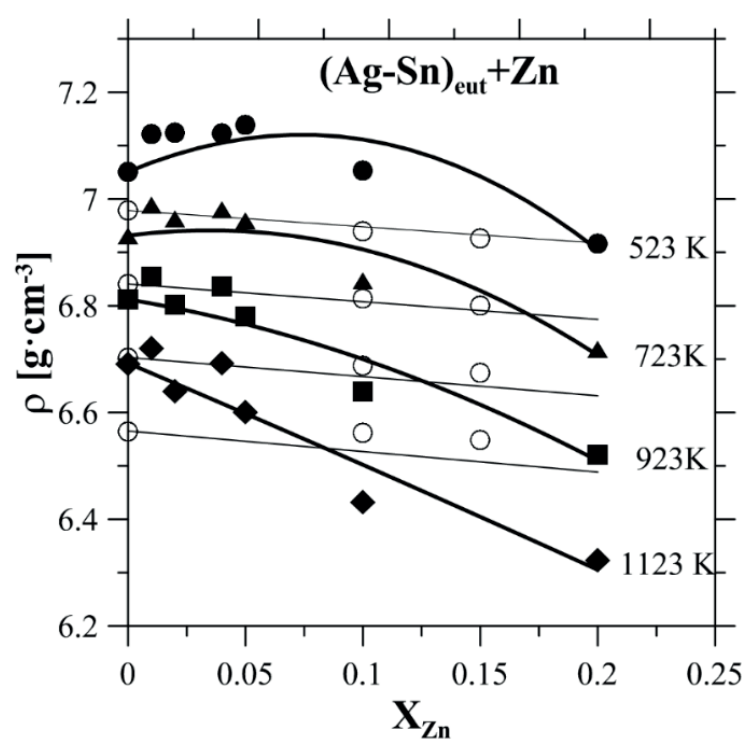

Fig. 3. Density isotherms of the (Ag-Sn) $)_{\text {eut }}+\mathrm{Zn}$ liquid alloys. Black symbols show data obtained by equations in Table 1 and the lines denote the values recalculated by Eq. 12 .

Calculating the molar excess free energy based on the optimized parameter from [11], one can state that the Ag-Zn systems are characterized by a negative deviation from the ideal solutions in the entire composition range and that the Ag-Sn system possesses also negative deviations, except for a small region of a low Ag concentration, in which positive deviations are observed. And so, taking into account the conclusion written above, rather slight negative deviations of density should be observed in the case of the Ag-Sn eutectic, instead of the measured positive ones. However, one can notice that these positive deviations of $\mathrm{G}^{\text {ex }}$ for the $\mathrm{Ag}-\mathrm{Sn}$ liquid alloys in the mentioned concentration region could be the results of an experimental error and, in fact, these solutions can be characterized by small negative deviations from the ideal ones. Then, the Ag-Sn liquid solutions would be of negative deviations in the entire range of concentrations, similarly to the case of the Ag-Zn system, and the observed positive density deviation of the Ag-Sn eutectic alloy would be in accordance with the conclusion presented earlier for the lithium alloys. Based on this remark, one can try to explain the observed small positive density deviations of the (Ag-Sn) $)_{\text {eut }}+\mathrm{Zn}$ alloys by the growth of the zinc concentration.

The negative deviations of the Ag-Zn system are almost twice as low as those for the $\mathrm{Ag}-\mathrm{Sn}$ system at $523 \mathrm{~K}$. This means that a greater tendency for the formation of alloys is in the case of the Ag-Zn system. Assuming that, in the liquid Ag$\mathrm{Sn}$ alloys, associates of $\mathrm{Ag}_{3} \mathrm{Sn}$ exist (near the composition of the excess free energy maximum), it seems probable that they can be partly submitted by the AgZn associates, when $\mathrm{Zn}$ is added to the Ag-Sn eutectic. In this case, the number of AgZn $+\mathrm{Ag}_{3} \mathrm{Sn}$ associates would be higher in the ternary Ag-Sn$\mathrm{Zn}$ alloys in comparison to the amount of $\mathrm{Ag}_{3} \mathrm{Sn}$ in the $\mathrm{Ag}$ Sn liquid alloys. Because, in the associates, the interatomic distance is lower than that in the ideal solution, the density of the liquid Ag-Sn-Zn alloys in which the associates are present should be higher in comparison to the ideal one and the Ag-Sn solution. In this case, a growth of density should be observed, as is the case in this study. Together with the 
temperature increase, the difference between the excess Gibbs energies of the Ag-Sn and the Ag- Zn system becomes lower, the influence of the associates becomes increasingly lower, the solutions tend to be closer to the ideal ones, and the molar volume tends also to be closer to that of the ideal solutions. One should note that the experimental error also influences the values of density; however, if it is similar for all the studied samples, the observed increase tendency with the increasing concentration of zinc is very probable.

The surface tensions measured by the maximum bubble pressure method are shown in the graphical form in Fig. 4 and their elaborated linear equations are presented in Table 3

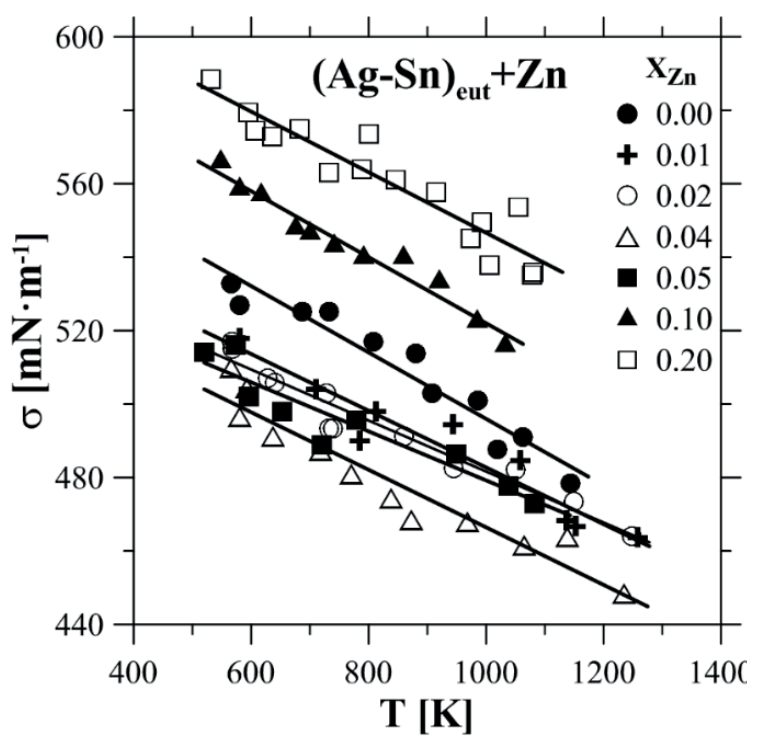

Fig. 4. Temperature dependences of the surface tension for the (Ag$\mathrm{Sn})_{\text {eut }}+\mathrm{Zn}$ liquid alloys. Symbols show the experimental data from these studies and the lines represent the values calculated by equations from Table 2

The values of surface tension calculated with the use of the Butler equation with different values of $\beta$ and A (Eqs 5-7 and $5,9,11$ ) are presented in Fig. 5.

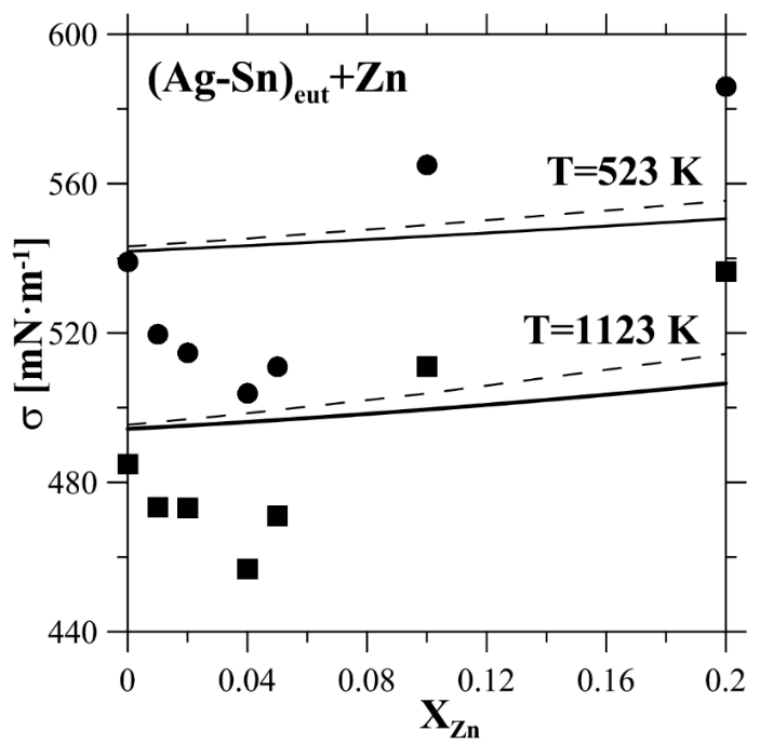

Fig. 5. Experimental isotherms of the surface tension of (Ag-Sn) ${ }_{\text {eut }}+\mathrm{Zn}$ liquid alloys (symbols) compared with the values obtained by equations 5-7, drawn as continuous lines, and those determined by Eqs 5, 9, 11, shown as dashed lines.

For the studied Ag-Sn-Zn alloys, no evident curve linear dependence of the surface tension vs. temperature was observed (Fig. 4). However, the differences between the experimental and the modelled values observed at the isotherms (Fig. 5) reach almost $40 \mathrm{mN} \cdot \mathrm{m}^{-1}$ and they are higher than the sum of the method measurement error, estimated in [27] at $1.5 \%$ of the measured value, and the maximal confidence interval calculated based on the analysis of the variance of the experimental data [26] $\left(15.1 \mathrm{mN} \cdot \mathrm{m}^{-1}\right)$. Moreover, the character of the changes of the experimental data for the alloys of the composition lower than $\mathrm{X}_{\mathrm{Zn}}=0.1$ is quite different than that of the calculated ones. The experimental surface tension isotherms possess the minimum near or at 0.04 mole fraction of $\mathrm{Zn}$, in contradiction to the modelled ones, which are characterized by a slow increase.

TABLE 3

Temperature dependences of surface tension for $(\mathrm{Ag}-\mathrm{Sn})_{\text {eut }}+\mathrm{Zn}$ liquid alloys with errors calculated for $\mathrm{A}$ and $\mathrm{B}$ equation parameters and density error calculated at $923 \mathrm{~K}$

\begin{tabular}{|c|c|c|c|c|}
\hline \hline $\mathbf{X}_{\mathbf{Z n}}$ & $\begin{array}{c}\boldsymbol{\sigma}=\mathbf{A}+\mathbf{B} \cdot \mathbf{T} \\
\mathrm{mN} \cdot \mathrm{m}^{-1}\end{array}$ & $\begin{array}{c}\boldsymbol{\sigma}_{923 \mathbf{K}} \\
\mathrm{mN} \cdot \mathrm{m}^{-1}\end{array}$ & $\begin{array}{c}\text { Err(A) } \\
\mathrm{mN} \cdot \mathrm{m}^{-1}\end{array}$ & $\begin{array}{c}\text { Err(A) } \\
\mathrm{mN} \cdot \mathrm{m}^{-1} \cdot \mathrm{K}^{-1}\end{array}$ \\
\hline $0.0000^{*}$ & $586.4-0.0904 \cdot \mathrm{T}$ & $502.9 \pm 11.1$ & \pm 15.6 & \pm 0.0179 \\
\hline 0.0100 & $560.0-0.0772 \cdot \mathrm{T}$ & $488.7 \pm 12.9$ & \pm 19.1 & \pm 0.0199 \\
\hline 0.0200 & $551.1-0.0694 \cdot \mathrm{T}$ & $487.0 \pm 8.9$ & \pm 9.8 & \pm 0.0116 \\
\hline 0.0400 & $544.8-0.0784 \cdot \mathrm{T}$ & $472.5 \pm 12.3$ & \pm 13.8 & \pm 0.0161 \\
\hline 0.0500 & $546.0-0.0668 \cdot \mathrm{T}$ & $484.4 \pm 12.9$ & \pm 16.8 & \pm 0.0212 \\
\hline 0.1000 & $612.0-0.0899 \cdot \mathrm{T}$ & $528.9 \pm 7.3$ & \pm 10.5 & \pm 0.0134 \\
\hline 0.2000 & $629.2-0.0825 \cdot \mathrm{T}$ & $553.0 \pm 12.5$ & \pm 14.5 & \pm 0.0170 \\
\hline
\end{tabular}


The reason of such behaviour can be related either to the thermodynamics $\left(\mathrm{G}^{\mathrm{ex}}\right)$ or the partial molar surface area of the components $\left(\mathrm{A}_{\mathrm{i}}\right)$ in the monoatomic surface layer for the dilute solutions (very low concentration of $\mathrm{Zn}$ and $\mathrm{Ag}$ ). This conclusion results directly from Eq. 5 because only these two parameters influence the results of the surface tension calculation. It seems also probable that the observed lowering of the surface tension of the (Ag-Sn) $)_{\text {eut }}+\mathrm{Zn}$ alloys could be the effect of the formation of slight amounts of zinc oxide and its accumulation in the monoatomic surface layer. The small impact of the alloys' density increase with the growth of the $\mathrm{Zn}$ concentration also causes a small decrease of the surface tension. The modelled surface tension of $(\mathrm{Ag}-\mathrm{Sn})_{\text {eut }}+\mathrm{Zn}$ with the use of the relations for $\beta$ and the monoatomic surface layer area $A_{i}$ proposed in $[29,30]$ gave values which were a bit closer to the experimental ones for $\mathrm{X}_{\mathrm{Zn}}=0.1$ and 0.2 .

The compositions of the monoatomic surface phase which were calculated with the application of Eqs 5-7 (model BHMT) or Eqs 5, 9 and 11 (model BG) are shown in Figs 6-8.

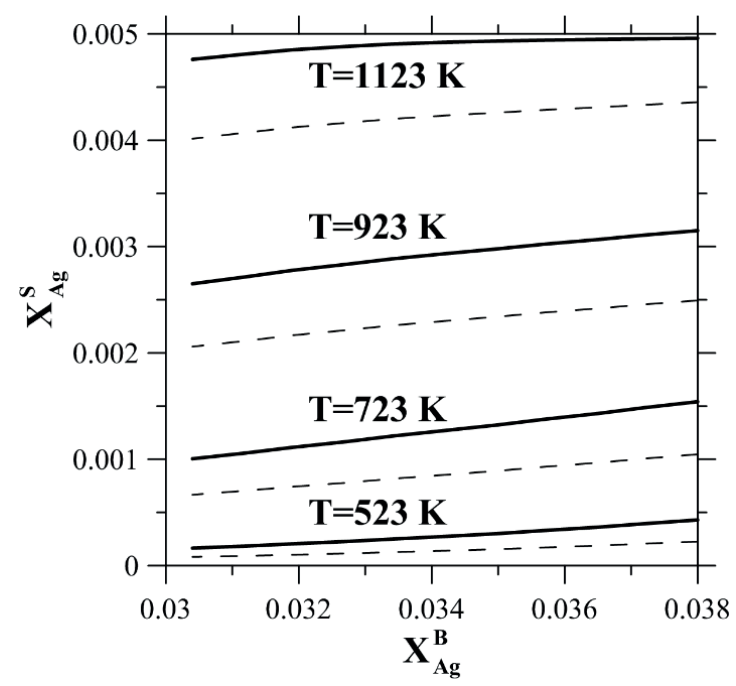

Fig. 6. Isotherms of $\mathrm{Ag}$ surface concentration as a function of $\mathrm{Ag}$ concentration in the bulk phase. Continuous and dashed lines show the values calculated by BHMT and BG model, respectively

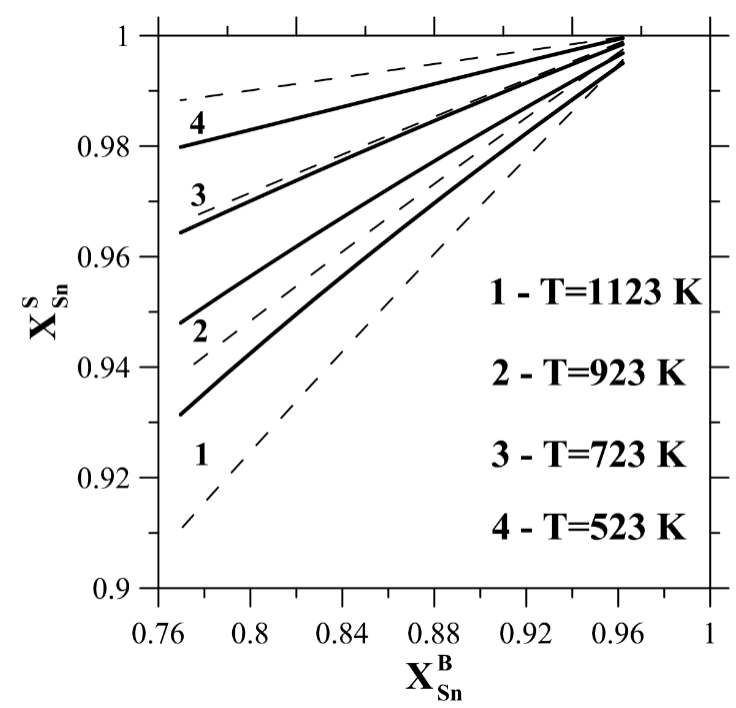

Fig. 7. Isotherms of $\mathrm{Sn}$ surface concentration as a function of $\mathrm{Sn}$ concentration in the bulk phase. Continuous and dashed lines show the values calculated by BHMT and BG model, respectively

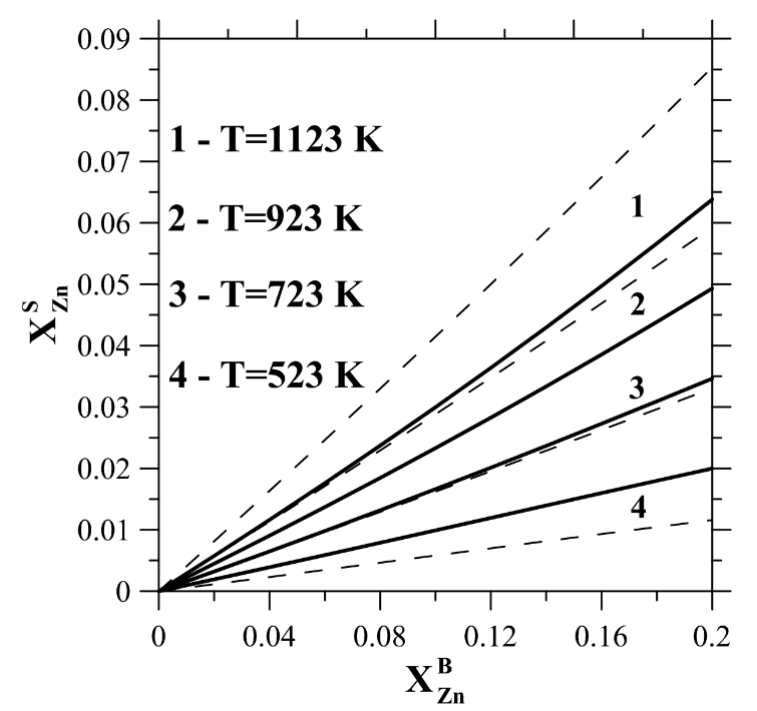

Fig. 8. Isotherms of $\mathrm{Zn}$ surface concentration as a function of $\mathrm{Zn}$ concentration in the bulk phase. Continuous and dashed lines show the values calculated by BHMT and BG model, respectively

As the calculations show, the addition of $\mathrm{Zn}$ to the $\mathrm{Ag}-\mathrm{Sn}$ eutectic decreases the concentration of $\mathrm{Ag}$ and $\mathrm{Zn}$ and increases that of tin in the monoatomic surface layer in comparison to those in the bulk phase. The growth of temperature causes a decrease of the tin concentration and an increase of the zinc and silver concentration in the monolayer. This tendency concerns both discussed models.

The silver concentration calculated from the $\mathrm{BG}$ model is always lower than that obtained from the BHMT one. In the case of $\mathrm{Sn}$ and $\mathrm{Zn}$, their concentrations in the monolayer change inversely. When, at any temperature, the concentration of tin calculated from the BG model is higher in comparison to that obtained from the BHMT one, the concentration of zinc is lower and inversely. It can be noticed from the analysis of Figs 6-8 that the increase of zinc in the bulk phase lowers the silver and zinc concentration and increases the tin concentration in the surface monolayer. The largest percentage change in comparison to that in the bulk phase is observed for silver. The small changes of the tin concentration in the surface phase result in a slight increase of the surface tension with the increasing concentration of zinc.

\section{Conclusions}

The investigations of the $(\mathrm{Ag}-\mathrm{Sn})_{\text {eut }}+\mathrm{Zn}$ alloys showed that the temperature dependence of the studied alloys is linear both in the case of the density and the surface tension.

The experimental investigations of the density and surface tension of the $(\mathrm{Ag}-\mathrm{Sn})_{\text {eut }}+\mathrm{Zn}$ lead-free solders show a varying influence of zinc on both properties.

It was found that the increase of the $\mathrm{Zn}$ concentration from 0 to 0.04 mole fraction in the studied alloys causes a decrease of the surface tension and an increase of the density, especially at lower temperatures. In the case of the molar volume, the influence of $\mathrm{Zn}$ is contrary to that for the density.

The modeled values of the surface tension for the alloys with a lower concentration of $\mathrm{Zn}$ possess higher values, 
and for the alloys with $X_{\mathrm{Zn}} \geq 0.1$ - lower values than the experimental data.

The surface tension modeled with the use of the values for $\beta$ and Ai proposed by Gąsior is a little bit closer to the experimental ones for $\mathrm{X}_{\mathrm{Zn}} \geq 0.1$. The observed minimum of the surface tension for the alloys of the concentration lower than $\mathrm{X}_{\mathrm{Zn}}=0.1$ is impossible to be modelled with the use of the given $\mathrm{G}^{\mathrm{ex}}, \beta$ and $\mathrm{A}_{\mathrm{i}}$ data.

The metal concentration calculated in the monoatomic surface layer showed that the addition of $\mathrm{Zn}$ to the $\mathrm{Ag}-\mathrm{Sn}$ eutectic lowers the silver and zinc concentration and increases the tin concentration in the monolayer.

Taking into account the high affinity of $\mathrm{Zn}$ to oxygen and water (vapour) and the most probable influence of the reaction product $(\mathrm{ZnO})$ on the surface tension, one can assume that the experimental and the modelled data can be thought as compatible.

\section{REFERENCES}

[1] W. Gąsior, Z. Moser, J. Pstruś, Journal of Phase Equilibria 22, 20-25 (2001)

[2] W. Gąsior, Z. Moser, J. Pstruś,, M. Kucharski, Archives of Metallurgy 46, 23-32 (2001).

[3] Z. Moser, W. Gąsior, J. Pstruś, Journal of Phase Equilibria 22 , 254-258 (2001).

[4] W. Gąsior, Z. Moser, J. Pstruś, K. Bukat, R. Kisiel, J. Sitek, Journal of Phase Equilibria 25, 115-121 (2004).

[5] P. Sebo, Z. Moser, P. Svec, D. Janickovic, E. Dobrocka, W. Gąsior, J. Pstruś, Journal of Alloys and Compounds 480, 409-415 (2009).

[6] Moser Z., Sebo P., Gasior, W. Svec, P. Pstruś, J., Calphad 33, 63-68 (2009).

[7] Z. Moser, W. Gąsior, K. Bukat, J. Pstruś, R. Kisiel, J. Sitek, K. Ishida, I. Ohnuma, Journal of Phase Equilibria and Diffusion, 28, 433-438 (2007).

[8] Fima P., Gąsior W., Sypień A., Moser Z., Journal of Materials Science 45, 4339-4344 (2010).

[9] Z. Moser, W. Gąsior, K. Bukat, J. Pstruś, R. Kisiel, J. Sitek, K. Ishida, I. Ohnuma, Journal of Phase Equilibria and Diffusion 28, 433-438, (2007),

[10] P. Terzieff, Physica B 405, 2668-2672 (2010).

[11] H. Ohtani, S. Ono, K. Doi, M. Hasebe, Materials Transactions 45, 614-624 (2004)

[12] S. Sugden, J. Chem. Soc. 124, 27 (1924).
[13] Z. Moser, W. Gąsior, J. Pstruś, K. Ishida, I.Ohnuma, R. Kainuma, S. Ishihara, and X. J. Liu, Materials Transaction 45, 652-660 (2004).

[14] J.A.V. Butler, Proc. Roy. Soc. 135A, 348-358 (1932).

[15] T.P. Hoar, A. A. Melford, Trans. Faraday Soc. 53, 315-326 (1957).

[16] T. Tanaka, K. Hack, T. Iida, and S. Hara, Z. Metallkd. 87, 380385 (1996).

[17] Z. Moser, W. Gąsior, J. Pstruś, Journal of Phase Equilibria 22, 254-258 (2001). AgSn

[18] W. Gąsior, Z. Moser, J. Pstruś, Journal of Phase Equilibria 24, 504-510 (2003). SbSn

[19] W. Gąsior, Z. Moser, J. Pstruś, A. Krzyżak, K. Fitzner, Journal of Phase Equilibria 24, 504-510 (2003). AgBi

[20] Z. Moser, W. Gąsior, J. Pstruś, W. Zakulski, I. Ohnuma, X.J. Liu, Y. Inohana, K. Ishida, Journal of Electronic Materials 30, 1120-1128 (2001). AgIn

[21] Z. Moser, W. Gąsior, J. Pstruś, Journal of Electronics Materials 30, 1104-1111 (2001).BiSn

[22] Wł. Gąsior, Modelowanie właściwości termodynamicznych z pomiarów napięcia powierzchniowego, Polska Akademia Nauk, Instytut Metalurgii i Inżynierii Materiałowej im. A. Krukowskiego, Kraków 2006. ISBN 83-921845-3-x. (in Polish).

[23] W. Gąsior, Archives of Metallurgy and Materials 51, 317-326 (2006).

[24] W. Gąsior, Archives of Metallurgy and Materials 51, (2006) 327-334.

[25] W. Gąsior, P. Fima, Z. Moser, Archives of Metallurgy and Materials 56, 13-23 (2011).

[26] W. Volk, Applied Statistics for Engineers, McGraw-Hill Book Company, New York, 2nd. p.260, Ed.1969.

[27] J. Pstruś, Praca doktorska, Kraków.

[28] J. Pstruś, Z. Moser, W. Gąsior, A. Dębski, Archives of Metallurgy and Materials 51, 335-343 (2006).

[29] W. Gąsior, Z. Moser, J. Pstruś, Journal of Phase Equilibria 19, 234-238 (1998)

[30] W. Gąsior, Z. Moser, J. Pstruś, Journal of Phase Equilibria 19, 568-571 (1998).

[31] W. Gąsior, Z. Moser, J. Pstruś , Archives of Metallurgy 48, 497-505 (2003)

[32] H. Ruppersberg, J. Saar, W. Speicher, P. Hejtjans, J. de Physique, Colloque C8 41, (1980) 595-598.

[33] H. Ruppersberg, W. Speicher, Z. Natruforschung 31, 47-52 (1976).

[34] R. Thuemmel, W. Klemm, Z. Anorg. Allgem. Chem. 376, 4463 (1970). 
